\title{
A population-based prevalence survey of known diabetes mellitus in Northern Italy based upon multiple independent sources of ascertainment*
}

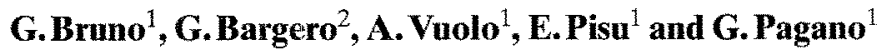 \\ ${ }^{1}$ Institute of Internal Medicine, University of Turin, ${ }^{2}$ Saint Spirit Hospital, Casale Monferrato, Alessandria, Italy
}

\begin{abstract}
Summary. The aims of this survey were (1) to estimate the prevalence of known diabetes mellitus in 1988 in Casale Monferrato (Northern Italy); (2) to validate different data sources available in Italy; (3) to identify a population-based cohort of diabetic patients. Multiple independent data sources were used and the capture-recapture method was applied to estimate the completeness of ascertainment of the survey. The primary data source was the list of all patients attending the diabetic clinic or those referred by family physicians and paediatricians of the area. The secondary data sources were the list of hospital discharges, the prescriptions data source and the list of all people using reagent strips and insulin syringes. On 1 October 1988 (the cut-off date) 2,069 cases of known diabetes were identified. The estimated completeness of ascertainment of the survey was $91 \%$. Prevalence of known diabetes, Type 1 (insulin-dependent), Type 2 (non-insulin-dependent) and insulin-treated diabetes were, respec-
\end{abstract}

tively, $2.21 \%(95 \%$ CI $2.13-2.29), 0.80 / 1,000(0.62-0.98)$ and $2.10 \%(2.01-2.19), 2.92 / 1,000(2.57-3.27)$. A higher prevalence of Type 2 diabetes was observed in women $(2.30 \%$, $2.18-2.42)$ than in men $(1.88 \%, 1.76-2.00)$. Age-specific prevalence of Type 2 diabetes increased with age. Computerized data sources routinely available in the Piedmont Region (hospital discharges and prescriptions data sources) showed a low completeness of ascertainment when considered together $(65 \%, 1,338$ of 2,069$)$, indicating the need to involve the diabetic clinic and family physicians in the ascertainment of known diabetes. In conclusion, the prevalence of known diabetes in Italy was lower than in Northern Europe and the United States.

Key words: Epidemiology, prevalence of diabetes mellitus, population survey, Italy.
Prevalence of diabetes mellitus differs widely among different populations [1]. However, only limited comparisons with Mediterranean countries are possible because of the few studies available for this area $[2,3]$.

In Italy, estimations based either upon drug consumption by applying the defined daily dose (DDD) [4] or upon prescriptions data source [5] suggested a low prevalence of the disease. These data were consistent with some previous studies [6-8] but were in disagreement with others [9].

Therefore, no reliable data on prevalence of diabetes or on clinical features of patients are available in Italy, although there is evidence to suggest a low risk for the disease.

The capture-recapture method, widely employed in the past by wildlife biologists and recently in human epidemiology [10-13], allows the completeness of ascertainment of surveys based upon multiple independent data

\footnotetext{
* Parts of this study were presented at the 14th Congress of the Inter-
} national Diabetes Federation, Washington, D.C., 23-28 June 1991 sources to be assessed, resulting in an accurate estimation of occurrence of noncommunicable diseases. We have undertaken this study to test the hypothesis of a low prevalence of diabetes in Northern Italy by using multiple independent sources of ascertainment of cases. The aims of this survey were: (1) to measure the prevalence of known diabetes in a geographically defined community in Northern Italy; (2) to validate different sources of ascertainment available in Italy; (3) to identify a populationbased cohort of diabetic patients for future epidemiological studies on diabetes.

\section{Subjects and methods}

The residents of the area of Casale Monferrato (Northern Italy) with a previous diagnosis of Type 1 (insulin-dependent) or Type 2 (noninsulin-dependent) diabetes and alive on the cut-off date of $1 \mathrm{Oc}$ tober 1988 were used as the study base. The total population of Casale Monferrato, which is mainly a rural area, was estimated as 93,477 from the intercensual estimates of 1987. 
Table 1. Prevalent cases of known diabetes mellitus for residents of Casale Monferrato on 1 October 1988 by source of ascertainment

\begin{tabular}{|c|c|c|c|c|}
\hline \multirow{2}{*}{$\begin{array}{l}\text { Cases } \\
(n)\end{array}$} & \multicolumn{4}{|l|}{ Source } \\
\hline & $\begin{array}{l}\text { Diabetic clinic } \\
\text { and/or family } \\
\text { physicians } \\
\text { (primary) }\end{array}$ & $\begin{array}{l}\text { Hospital } \\
\text { discharges } \\
\text { (secondary) }\end{array}$ & $\begin{array}{l}\text { Prescriptions } \\
\text { (secondary) }\end{array}$ & $\begin{array}{l}\text { Reagent } \\
\text { strips and } \\
\text { insulin } \\
\text { syringes } \\
\text { (secondary) }\end{array}$ \\
\hline 58 & $X$ & $X$ & $\mathrm{X}$ & $X$ \\
\hline 157 & $X$ & $X$ & $\mathrm{X}$ & \\
\hline 18 & $X$ & $X$ & & $\mathrm{X}$ \\
\hline 46 & $X$ & & $\mathrm{X}$ & $X$ \\
\hline 104 & $x$ & $\mathrm{X}$ & & \\
\hline 650 & $\mathrm{X}$ & & $\mathrm{X}$ & \\
\hline 12 & $\mathrm{X}$ & & & $X$ \\
\hline 709 & $X$ & & & \\
\hline 14 & & $\mathrm{X}$ & $X$ & $\mathrm{X}$ \\
\hline 20 & & $X$ & $X$ & \\
\hline 7 & & $\mathrm{X}$ & & $\mathrm{X}$ \\
\hline 8 & & & $\mathrm{X}$ & $X$ \\
\hline 74 & & $X$ & & \\
\hline 182 & & & $X$ & \\
\hline 10 & & & & $\mathrm{X}$ \\
\hline 2069 & 1754 & 452 & 1135 & 173 \\
\hline
\end{tabular}

Multiple independent sources of cases were used to ensure a case ascertainment as complete as possible and to estimate the completeness of the survey.

The first data source was the list of all patients with a previous diagnosis of Type 1 or Type 2 diabetes on the cut-off date, attending the diabetic clinic of the area. Criteria used to confirm a previous diagnosis of diabetes were those defined by the National Diabetes Data Group (NDDG) [14]. A list of all patients identified through this data source was submitted to all family physicians and paediatricians of the area; they were asked to refer all patients with a previous diagnosis of Type 1 or Type 2 diabetes on the cut-off date, identified during a 9-month period and not previously ascertained through the diabetic clinic. Meetings were organized with small numbers of physicians to present the aims of the study, to standardize the diagnosis of diabetes and to increase compliance. All 98 family physicians and paediatricians of Casale Monferrato agreed to take part. Since these two data sources (diabetic clinic, family physicians and paediatricians) were not independent, they were considered together as primary data source when applying the capture-recapture method to estimate the completeness of ascertainment.

The second data source was the list of hospital discharges for all public and private hospitals of the Piedmont Region, where Casale Monferrato is located. Records were available for $90 \%$ of discharges during 1976-1985 and for 80\% in 1986-1988. A list of all patients discharged with a primary or secondary diagnosis of diabetes (International Classification of Diseases 250.0) and residents of Casale Monferrato was checked.

The third data source was the computerized data base of insulin and oral hypoglycaemic prescriptions for 1988. All Italian citizens are included in the National Health System (NHS); hypoglycaemic drugs prescribed by physicians contracted by the NHS are dispensed through public and private pharmacies which are then reimbursed by the health authorities. Prescription forms, which are standardized throughout Italy, are routinely collected from all Italian pharmacies; in the Piedmont Region, they are usually recorded $100 \%$ in three non-consecutive months/years and $10 \%$ in the remaining months. The data base includes the NHS identification number for both the prescription holder and the family physician. Whereas the accuracy of drug prescription data is high, the accuracy of patient's code, which is not directly related to payment procedure, is lower. When the latter was not available on data base because of errors in transcription or registration or both, prescriptions were manually checked by one of us (GB).
The fourth data source was the list of all residents of the area of Casale Monferrato who requested a reimbursment for insulin syringes and reagent strips.

The list of all patients identified through any secondary data source and not previously ascertained through the primary data source was verified by asking family physicians and paediatricians to confirm the diagnosis of diabetes. For subjects who died in the meantime, the exact date of death was obtained from public registries and further information on the disease was collected from family physicians. After linkage between primary and secondary data sources, individual data were coded in order to maintain patient anonymity.

Criteria used to confirm a previous diagnosis of diabetes were those defined by the NDDG [14]. For the purpose of this survey, patients were classified as Type 1 diabetic if they were $0-30$ years at diagnosis of diabetes and insulin-treated within 2 years and as Type 2 diabetic if they were over 30 years at diagnosis, irrespective of treatment.

\section{Statistical analysis}

Results are presented as percentage or means \pm SD. Student's unpaired $t$-test or chi-square test were performed to compare means for continuous variables or percentage for discrete variables. The completeness of ascertainment of the survey was computed with the capture-recapture method according to the Chapman estimator $[10-13]$ as the proportion between the observed and the estimated number of prevalent cases. The $95 \%$ confidence intervals (CI) of point estimates of $\mathrm{N}$ was $\mathrm{N} \pm 1.96$ times variance. Denominators of prevalence data were from the intercensual estimates of $1987 . \mathrm{CI}$ were prevalence \pm 1.96 times $\mathrm{SE}(p)$ [15].

\section{Results}

From the residents of the area of Casale Monferrato on the cut-off date, 1 October 19882,069 cases of known diabetes were identified.

Through the primary data source 1,754 cases were identified (Table 1). Of these, 1,520 were identified through the diabetic clinic and 234 through family physicians and paediatricians.

The hospital discharge data source identified 1,224 residents of Casale Monferrato discharged with a diagnosis of diabetes during the period 1976-1988. Of these, 684 had died or moved before the cut-off date. In the remaining 540 subjects, the validity of diagnosis of diabetes, as assessed by family physicians, showed that $88(16 \%)$ were not diabetic and $452(84 \%$ ) were diabetic; of these, $115(25 \%)$ had not been previously identified through the primary data source.

The insulin and oral hypoglycaemic prescriptions data source recorded 6,276 prescriptions in 1988. For 3,412 prescriptions ( $54 \%$ ), the NHS patient identification number was available and allowed the identification of 1,085 subjects; of these, $58(5 \%)$ were not diabetic, $54(5 \%)$ had moved or died before the cut-off date and $973(90 \%)$ were diabetic. Of the remaining 2,864 prescriptions, we manually checked 1,121 (39\%), recorded in April, September and November of 1988, for which the file was exhaustive; 162 diabetic patients were found, who were not previously identified through the primary data source.

Therefore, the prescriptions data source identified $1,135(55 \%, 1,135$ of 2,069$)$ diabetic patients, $224(20 \%)$ of whom had not been previously ascertained through the primary source. 
Table 2. Prevalence of known diabetes mellitus on 1 October 1988 in Casale Monferrato

\begin{tabular}{lrll}
\hline & $\begin{array}{l}\text { Cases } \\
(n)\end{array}$ & & $\begin{array}{l}95 \% \\
\text { confidence interval }\end{array}$ \\
\hline Type 1 & 77 & $0.80 / 1,000$ & $(0.62-0.98)$ \\
Type 2 & 1967 & $2.10 \%$ & $(2.01-2.19)$ \\
$\begin{array}{l}\text { Unclassified } \\
\text { diabetes }\end{array}$ & 25 & $0.27 / 1,000$ & $(0.16-0.38)$ \\
$\begin{array}{l}\text { Overall known } \\
\text { diabetes }\end{array}$ & 2069 & $2.21 \%$ & $(2.13-2.29)$ \\
\hline
\end{tabular}

Table 3. Age-specific prevalence rates per 1,000 of insulin-treated diabetes on 1 October 1988 in Casale Monferrato

\begin{tabular}{llll}
\hline $\begin{array}{l}\text { Age } \\
\text { (years) }\end{array}$ & $\begin{array}{l}\text { Cases } \\
(n)\end{array}$ & $\begin{array}{l}\text { Age specific } \\
\text { prevalence } \\
\text { per } 1,000\end{array}$ & $\begin{array}{l}\text { 95\% confidence } \\
\text { interval }\end{array}$ \\
\hline $0-30$ & 36 & 1.23 & $(0.83-1.63)$ \\
$31-39$ & 22 & 1.85 & $(1.08-2.62)$ \\
$40-49$ & 18 & 1.50 & $(0.88-2.12)$ \\
$50-59$ & 49 & 3.79 & $(2.91-4.67)$ \\
$60-69$ & 60 & 4.98 & $(3.74-6.22)$ \\
$70-79$ & 58 & 5.89 & $(4.50-7.28)$ \\
$>=80$ & 30 & 5.59 & $(3.63-7.55)$ \\
\hline Total & 273 & 2.92 & $(2.57-3.27)$ \\
\hline
\end{tabular}

Table 4. Prevalent cases of known Type 2 (non-insulin-dependent) diabetes on 1 October 1988 in Casale Monferrato by treatment and sex

\begin{tabular}{|c|c|c|c|c|c|c|}
\hline \multirow[t]{2}{*}{ Treatment } & \multicolumn{2}{|l|}{ Men } & \multicolumn{2}{|c|}{ Women } & \multicolumn{2}{|l|}{ Total } \\
\hline & $(n)$ & $\%$ & (n) & $\%$ & $(n)$ & $\%$ \\
\hline Diet & $(96)$ & 11.4 & (107) & 9.5 & (203) & 10.3 \\
\hline $\begin{array}{l}\text { Oral hypoglycaemic } \\
\text { drugs }\end{array}$ & $(644)$ & 76.9 & $(855)$ & 75.7 & (1499) & 76.2 \\
\hline Insulin & (79) & 9.5 & (117) & 10.4 & (196) & 10.0 \\
\hline $\begin{array}{l}\text { Insulin + oral hypo- } \\
\text { glycaemic drugs }\end{array}$ & (19) & 2.2 & $(50)$ & 4.4 & (69) & 3.5 \\
\hline Total & $(838)$ & 100 & (1129) & 100 & (1967) & 100 \\
\hline
\end{tabular}

The fourth data source identified 173 diabetic patients who requested reimbursement for reagent strips and insulin syringes, $39(23 \%)$ of whom had not been previously identified through the primary data source.

Computerized data sources routinely available in the Piedmont Region (hospital discharges and prescriptions data sources), when considered together, identified 1,338 of $2,069(65 \%)$ diabetic patients.

The estimated number of prevalent cases in the target population, according to the Chapman estimator, was 2,283 (95\% CI 2,240. 7-2,325.3).

$$
\begin{aligned}
\mathrm{N} & =\frac{(\mathrm{M}+1)(\mathrm{n}+1)}{(\mathrm{m}+1)}-1 \\
& =\frac{(1,754+1)(1,360+1)}{(1,045+1)}-1=2,283
\end{aligned}
$$

variance $(\mathrm{N})=\frac{(\mathrm{M}+1)(\mathrm{n}+1)(\mathrm{M}-\mathrm{m})(\mathrm{n}-\mathrm{m})}{(\mathrm{m}+1)^{2}(\mathrm{~m}+2)}=465.67$ where $\mathrm{N}$ is the estimated number of cases in the target population; $M$ is the number of cases identified in the primary source, 1,$754 ; \mathbf{n}$ is the number of cases identified in any secondary source, 1,360 ; and $m$ is the number of cases identified in both primary and secondary data sources, 1,045 .

Therefore, the estimated completeness of the primary data source was $77 \%(1,754 / 2,283)$ whereas the estimated completeness of the prevalence survey was $91 \%$ $(2,069 / 2,283)$.

Table 2 shows prevalence rates for Type 1, Type 2 and overall known diabetes. The overall prevalence of known diabetes was 2.21 (95\% CI 2.13-2.29).

Regarding the classification of diabetic patients as Type 1 or Type 2, for 25 patients neither age at diagnosis nor type of treatment were available on case records. Of the remaining $2,044,77$ were $0-30$ years at diagnosis, insulin-treated within 2 years after diagnosis and therefore defined as Type 1 diabetic; the remaining 1,967 were over 30 years at diagnosis of diabetes and therefore defined as Type 2 diabetic. The prevalence of Type 1 diabetes was 0.80 per $1,000(0.62-0.98)$; the mean age at diagnosis and current age were, respectively, $19.17 \pm 8.0$ years and $35.1 \pm 16.9$ years, with a mean duration of $16.0 \pm 14.9$ years.

The prevalence of insulin-treated diabetes was 2.92 per 1,000 (2.57-3.27). Table 3 shows age-specific prevalence rates per 1,000 of insulin-treated diabetes. Of 273 cases identified, $196(72 \%)$ were over 30 years at diagnosis of diabetes. The overall proportions of patients insulintreated within 1 year after diagnosis were $56.6 \%$ (120 of 212 ) and $32 \%$ (43 of 135), respectively, for all age groups and for the age group over 30 years at diagnosis, after excluding patients with an unknown interval between diagnosis and start of insulin treatment (61 of 273). In all patients diagnosed under the age of 30 years, insulin was started within 1 year after diagnosis, while this proportion decreased with increasing age at diagnosis. Prevalence rates for diabetic patients starting permanent insulin treatment within 1 year after diagnosis were 1.28 per 1,000 $(1.05-1.51)$ and 0.46 per $1,000(0.32-0.60)$, respectively, in those aged $0-30$ years at diagnosis and in those diagnosed at over 30 years of age.

The overall prevalence (\%) of known Type 2 diabetes was 2.10 (2.01-2.19). Figure 1 shows the age-specific prevalence rates. The sex-specific prevalence rates (\%) were $1.88(1.76-2.00)$ in men and $2.30(2.18-2.42)$ in women. The male to female ratio of sex-specific prevalence was 0.82 ; an excess of men was evident in the $40-49$ year agegroup (male to female ratio 1.45) whereas an excess of women was evident in older age groups, although not significant. Men had a younger age at diagnosis ( $57.39 \pm 11.35$ years vs $60.03 \pm 11.61$ years), a shorter duration of the disease $(7.34 \pm 6.66$ years vs $8.36 \pm$ 7.38 years $)$ and a younger current age $(64.74 \pm 10.57$ years vs $68.39 \pm 10.73$ years). A family history of diabetes in parents was found in $33 \%$ of diabetic patients.

As regards therapeutic patterns (Table 4), 10.3\% diabetic subjects were treated with diet alone, $76.2 \%$ with oral hypoglycaemic drugs, $10.0 \%$ with insulin and $3.5 \%$ with both insulin and oral hypoglycaemic drugs. Of 


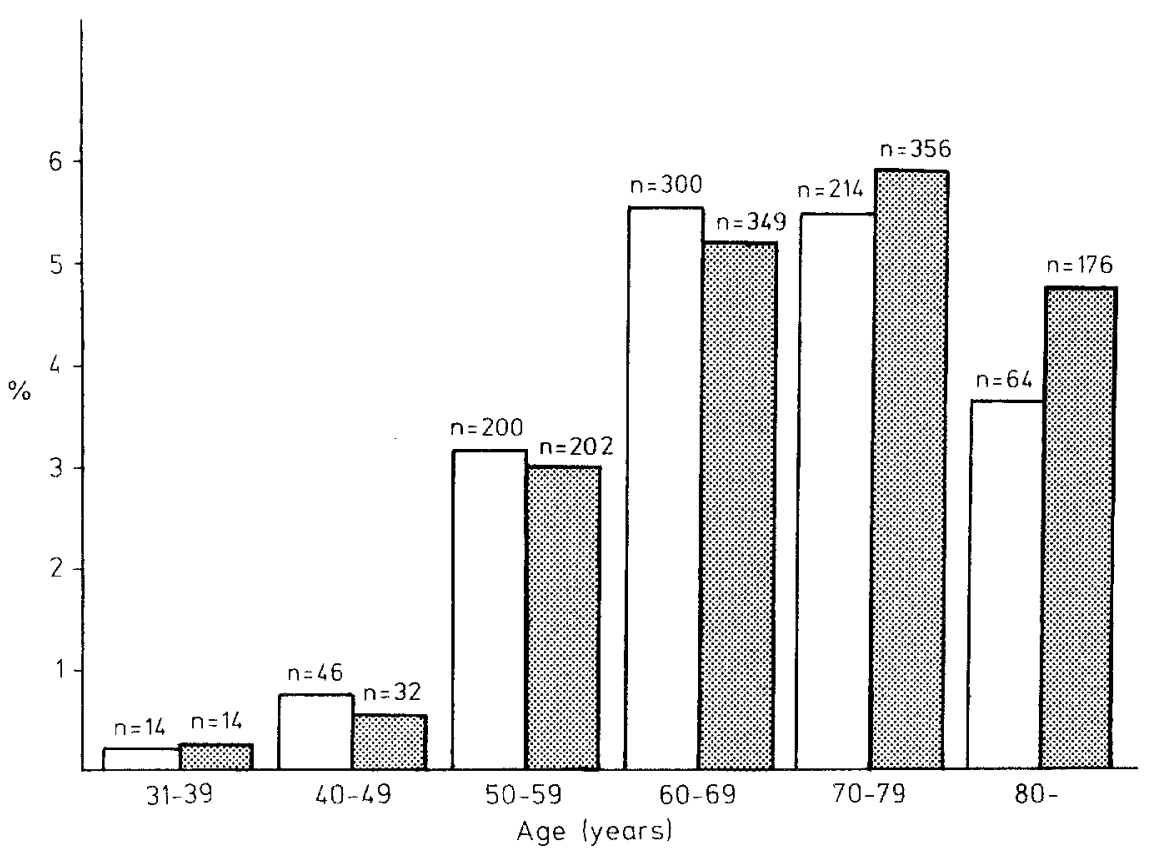

Fig.1. Age-specific prevalence rates (\%) of known Type 2 (non-insulin-dependent) diabetes in residents of Casale Monferrato on 1 October 1988 , in men $(\square)$ and women (屃) diabetic patients treated with oral hypoglycaemic drugs, $65.1 \%$ were treated with sulphonylureas, $0.26 \%$ with biguanides and $34.6 \%$ with both. The average number of tablets per day of oral hypoglycaemic drugs and total insulin units dosage per day were, respectively, $1.38 \pm 1.07$ tablets per day and $33.03 \pm 15.43 \mathrm{IU}$ per day. No significant differences were found between men and women $(p>0.01)$.

\section{Discussion}

While some diabetes prevalence surveys have been performed in Northern Europe [16-21], few studies are available at present for the Mediterranean area [2,3]. In Italy, screening programmes performed in the past resulted in different estimates, ranging from $1.03 \%$ in the $30-70$ year age group [7] to $11.2 \%$ in the 20 year and over age group [9]. However, these studies were hampered either by a low response rate $(45-55 \%)$ [6-8] or by non-random selection of subjects [9]; different diagnostic criteria were adopted, as fasting blood glucose level $7.8 \mathrm{mmol} / \mathrm{l}$ and over [8], the sum of fasting and post-load glucose levels $27.8 \mathrm{mmol} / 1$ and over [6] or those defined by WHO [9,22]. In a small rural population of Southern Italy, a prevalence of known diabetes of $4 \%$ was found based on 43 diabetic patients identified with a screening programme [22]. A study conducted in San Marino, with case ascertainment based only on diabetic clinic attendance, showed a prevalence of $1.85 \%$ in men and $1.94 \%$ in women [23]. In Vicenza, a survey based on prescriptions and hospital discharge records found a prevalence of $2.07 \%$ [24]. Two recent studies based either on drug consumption, by applying the DDD [4], or upon the analysis of prescriptions in Pozzuoli [5] estimated a prevalence of $1.7 \%$ and $2.4 \%$, respectively.

This survey, based on four independent data sources, showed a prevalence of known diabetes that was higher than the estimate based on the DDD [4]; and comparable with the studies performed in Vicenza [24] and Pozzuoli [5].

In comparison with the United States [25-26] and Northern Europe [16-21], the prevalence of known diabetes in Casale Monferrato was low. This might reflect either differences in incidence or in survival [27]; at present, however, no incidence or mortality data of diabetes in an Italian population are available to explain the prevalence we found. Comparisons of occurrence of diabetes could be biased by differences in screening by family physicians in different areas. In Italy, a prevalence of known diabetes almost equal to that of unknown diabetes has been shown in a screening programme based on the oral glucose tolerance test and WHO criteria in the age group over 18 years ( $3.2 \%$ vs $3.7 \%$ ) [22]. Another study based on fasting glucose levels of $7.8 \mathrm{mmol} / 1$ and over, found prevalence rates of $2.2 \%$ and $1.45 \%$, respectively, of known and unknown diabetes in the 20-59 year age group, probably because of the lower sensitivity of this test to detect unknown diabetes [8].

The classification of diabetic patients into either Type 1 or Type 2 according to NDDG criteria is often difficult in patients over 30 years at diagnosis [28]. Age at diagnosis under 40 years and permanent insulin therapy within 2 years after diagnosis [29] or age under 40 years, $100 \%$ ideal body weight at diagnosis or C-peptide values less than $0.30 \mathrm{mmol} / 1$ or both [30] suggest Type 1 diabetes. In this survey, we used a more conservative approach by defining as Type 2 diabetic all patients diagnosed after 30 years, irrespective of treatment. Misclassification could have occurred, mainly for Type 1 diabetes developing in the 31-39 year age group; however, only 11 cases were insulin-treated within 2 years after diagnosis in this age group, which would have increased the prevalence of Type 1 diabetes from 0.80 to 0.90 per 1,000 .

In the present study, the prevalence of insulin-treated diabetes was lower than in Scotland [31], New Zealand 
[32] and Denmark [33]. Our rates remained lower when comparing prevalence of insulin-treated diabetes within a short period after diagnosis, which probably includes subjects with a slower progression towards insulin-dependent diabetes [34]. These results could depend either on differences in physicians' prescribing attitude or on a low incidence of Type 1 diabetes in the overall population, as described by surveys limited to the 0-29 year age group $[35,36]$.

This survey showed that the prevalence of Type 2 diabetes increased with age from $0.65 \%$ in the $40-49$ year age group to $5.78 \%$ in the $70-79$ year age group, confirming previous observations of worsening glucose tolerance with age [37]. The lower prevalence we found in the 80 years and over age group was probably caused by higher mortality rate. A significantly higher prevalence of diabetes was evident in women, confirming previous observations [5].

As regards therapeutic pattern of Type 2 diabetes, this survey showed a higher proportion of treatment with oral hypoglycaemic drugs, consistent with results from France [38]. In this survey, a very low consumption of biguanides was found, suggesting that sulphonylureas alone or combined with biguanides are the current treatment for most diabetic patients in this community.

Results of this study seem not to be affected by underascertainment of diabetes. The capture-recapture method allows the estimation of the true number of cases in a target population, if sources are independent. This assumption should be met in our survey, since the chances of a diabetic patient being ascertained through the secondary data sources should not be influenced by previous identification through the primary data source. Lack of independence of data sources would have biased our estimate, underestimating the real number of prevalent cases. The completeness of ascertainment of this survey can be considered high $(91 \%)$, given the difficulties encountered in population-based surveys when including Type 2 diabetes.

The second aim of this study was to validate different sources of case ascertainment routinely available in Italy. Neither hospital discharge nor prescription records were exhaustive, which probably explains the low completeness of ascertainment. As regards hospital discharges, under-reporting of diabetes on discharge records, or a low rate of hospitalization of diabetic patients living in this area could have occurred. These results indicate the need to involve the diabetic clinic and family physicians in the ascertainment of known diabetes in this area.

Finally, this study was useful in identifying a large population-based cohort of diabetic patients for future epidemiological studies on diabetes, lacking at present in Italy.

Acknowledgements. This work was supported by a grant from the Ministry of Public Health (scientific research 1987). We are grateful to Dr. L. Merlo, USL 76; Dr. P.Tofanini, Dr. P. Costanzo and Dr. G. Verrua, Saint Spirit Hospital, for cooperation provided by all $\mathrm{Na}$ tional Health Service units of USL 76. We are also grateful to Dr. P. Picollo, CED, Casale Monferrato; Dr. P.Pasino, CED Alessandria; Dr. G. Ottavis, Pharmaceutical Unit, USL 76 who provided access to the prescriptions data source. Drs. A. Caramellino, M. Capra
Marzani, A. Rosso, Nurses I. Camona, A. Raimondi and M. Bianco, Dieticians C. Cappa and D. Montemerlo were helpful collaborators of this study. We are grateful to Prof. F. Merletti for thoughtful advice. We would like to thank the members of the Casale Monferrato Family Physicians Study Group for their contribution to this study. The members are: A.Alesso, A.Angelini, M.Annarotone, C.Arena, F.Aviotti, A.Bagna, L.Balbo, G.Barigazzi, F.Barone, G.Battezzati, R.Bedon, M.Bertiglia, G.Bertinetti, P.L.Bigliati, G.Bocchino, F. Boero, F.Botto, U.Bozzelli, M.Busca, E. Cabiati, A. Calcagno, M. Capra, R. Caprioglio, G. Caprino, A. Caramellino, B.Carelli, G.Casalino, G.Casalone, G.Castelli, G.Coggiola, G.F.Coppo, N.Corda, P.M.Croce, G.Croppi, G.Crosio, M.De Alessi, N.Del Boca, P.Demarchi, P.Deregibus, M. Fasano, L. Formaggio, N.Forno, F.Gabba, M.Gallesi, D. Gavazza, G. Giorcelli, B. Giordano, C. Grangiotti, P. Graziano, R. Guaschino, F. Iacometti, G.P.Irico, P.L. Lavagno, L.Lavazza, P.Lavazza, M.L.Liverani, F.P.Longo, D.Maggi, N.Maltoni, L.Martinelli, M.Mazzucco, G. Mortara, M.L. Mosso, L. Musso, G. Negri, A. Oglietti, F. Ombra, E. Orcesi, V.Ottavis, S. Ottolenghi, A.Panattoni, F.Papili, V.Pasolini, R.Patrucco, G.Perani, G.D.Picasso, P.G.Pisano, F.Poncina, P.L.Porta, L.Ramezzana, C.Rendo, D.Robotti, L.Rondano, F.Rossi, G.Rosso, C.Spatazza, E.Spinoglio, F.Tedesco, E.Tosco, M. Tribocco, G. Trinchero, G. Vallaro, G. Varaldo, C. Verrua, G. Verrua, C.Zanello, G. Zavattaro, M.Zola.

\section{References}

1. Jarrett RJ (1989) Epidemiology and public health aspects of noninsulin-dependent diabetes mellitus. Epidemiol Rev 11: 151-171

2. Schranz AG (1989) Abnormal glucose tolerance in the Maltese: a population-based longitudinal study of the natural history of NIDDM and IGT in Malta. Diabetes Res Clin Pract 7: 7-16

3. Papoz L, Ben Khalifa F, Eschwege E, Ben Ayed H (1988) Diabetes mellitus in Tunisia: description in urban and rural populations. Int J Epidemiol 17: 419 422

4. Garancini P, Gallus G, Calori G, Formigaro F, Micossi P (1991) Incidence and prevalence rates of diabetes mellitus in Italy from routine data: a methodological assessment. Eur J Epidemiol 7: $55-63$

5. Palombino R, Vaccaro O, Morra G et al. (1990) Indagine epidemiologica sulla prevalenza del diabete mellito nell 'USL 22 della Regione Campania attraverso la prescrizione di farmaci. $G$ Ital Diabetol 10: 1-7

6. Pompei A, Mortola V, Brunetti F, Campodonico C (1982) Indagine epidemiologica sul diabete nella popolazione di Camogli. G Ital Diabetol 2: 83-91

7. Morsiani M, Beretta P, Pareschi PL, Manservigi D, Bottoni L (1985) Long term results in preventive medicine for type 2 diabetes. Acta Diabetol Lat 22: 191-202

8. Muntoni S, Pintus F, Mascia P et al. (1988) Indagine epidemiologica sul diabete noto e ignorato in Sardegna. G Ital Diabetol 8: $311-316$

9. Savagnone E, Cappello F, Caruso V et al. (1985) Indagine epidemiologica sul diabete mellito nella popolazione di Pantelleria (Sicilia). Note preliminari. G Ital Diabetol 5: 71-80

10. National Diabetes Data Group (1979) Classification and diagnosis of diabetes mellitus and other categories of glucose intolerance. Diabetes 28: 1039-1057

11. Cates W, Smith JC, Rochat RW, Patterson JE, Dolman A (1978) Assessment of surveillance and vital statistics data for monitoring abortion mortality, United States, 1972-1975. Am J Epidemiol 108: 200-206

12. Huether CA, Gummere GR (1982) Influence of demographic factors on annual Down's syndrome births in Ohio, 1970-1979, and The United States, 1920-1979. Am J Epidemiol 115: 846-860

13. Robles SC, Marrett LD, Clarke EA, Risch HA (1988) An application of capture-recapture methods to the estimation of completeness of cancer registration. J Clin Epidemiol 41: 495-501 
14. Cochi SL, Edmonds LE, Dyer K et al. (1989) Congenital rubella syndrome in The United States, 1970-1985. Am J Epidemiol 129: 349-361

15. Armitage P, Berry G (1987) Statistical methods in medical research, 2nd edn. Blackwell, Oxford, pp 117-120

16. Croxson SCM., Burden AC, Bodington M, Botha JL (1991) The prevalence of diabetes in elderly people. Diabetic Med 8: 28-31

17. Tuomilehto J, Nissinen A, Kivelä S-L et al. (1986) Prevalence of diabetes mellitus in elderly men aged 65 to 84 years in Eastern and Western Finland. Diabetologia 29:611-615

18. Damsgaard EM, Faber OK, Frøland A et al. (1987) Prevalence of fasting hyperglycemia and known non-insulin-dependent diabetes mellitus classified by plasma C-peptide: Fredericia survey of subjects 60-74 yr old. Diabetes Care 10:26-32

19. Mather HM, Keen H (1985) The Southall Diabetes Survey: prevalence of known diabetes in Asians and Europeans. Br Med J291: 1081-1084

20. Neil HAW, Gatling W, Mather HM (1987) The Oxford Community Diabetes Study: evidence for an increase in the prevalence of known diabetes in Great Britain. Diabetic Med 4:539_ 543

21. Wong JSK, Pearson DWM, Murchison L, Williams MJ (1991) The prevalence of diabetes mellitus in North East Scotland. Diabetic Med 8 [Suppl 1]: 28 (Abstract)

22. Verrillo A, De Teresa A, La Rocca S, Carandente Giarrusso P (1985) Prevalence of diabetes mellitus and impaired glucose tolerance in a rural area of Italy. Diabetes Res 2: 301-306

23. Simetovic N, Devoti G, Stefanelli L et al. (1990) Prevalenza del diabete manifesto nella Repubblica di San Marino. G Ital Diabetol 10: 263-269

24. Erle G, Gennaro R, Lora L, Basso A, Mingardi R, Piva I (1988) Studio epidemiologico del diabete mellito nell 'USL-Vicenza. Proposta di un nuovo metodo di indagine. G Ital Diabetol 8: 23-29

25. Harris MI, Hadden WC, Knowler WC, Bennett PH (1987) Prevalence of diabetes and impaired glucose tolerance and plasma glucose levels in U.S. population aged $20-74$ yr. Diabetes 36 : $523-534$

26. Barrett-Connor E (1980) The prevalence of diabetes mellitus in an adult community as determined by hystory or fasting hyperglycemia. Am J Epidemiol 111: 705-712

27. Rothman KJ (1986) Modern epidemiology. Little, Brown and Company, Boston, pp 33-34
28. Madsbad S (1990) Classification of diabetes in older adults. Diabetes Care 13 [Suppl 2]: 93-96

29. Welborg TA, Garcia-Webb P, Bonser A, McConn V, Constable I (1983) Clinical criteria that reflect C-peptide status in idiopathic diabetes. Diabetes Care 6: 315-316

30. Hother-Nielsen O, Faber O, Schwartz NS, Beck-Nielsen H (1988) Classification of newly diagnosed diabetic patients as insulin-requiring or non-insulin-requiring based on clinical and biochemical variables. Diabetes Care 11:531-537

31. Waugh NR, Jung RT, Newton RW (1989) The Dundee prevalence study of insulin-treated diabetes; intervals between diagnosis and start of insulin therapy. Diabetic Med 6:346-350

32. Scott RS, Brown LJ (1991) Prevalence and incidence of insulintreated diabetes mellitus in adults in Canterbury, New Zealand. Diabetic Med 8: 443-447

33. Green A, Hauge M, Holm NV, Rasch LL (1981) Epidemiological studies of diabetes mellitus in Denmark. II. A prevalence study based on insulin prescriptions. Diabetologia 20: 468-470

34. Groop LC, Bottazzo GF, Doniach D (1986) Islet cell antibodies identify latent Type 1 diabetes in patients aged $35-75$ years at diagnosis. Diabetes 35: 237-241

35. Bruno G, Merletti F, Pisu E, Pastore G, Marengo C, Pagano G (1990) Incidence of IDDM during 198486 in population aged $<30$ yr residents of Turin Italy. Diabetes Care 13: 1051-1056

36. Calori G, Gallus G, Garancini P, Repetto F, Micossi P (1990) Identification of a cohort of Type 1 diabetes presenting in Lombardy in 1983-1984: a validated assessment. Diabetic Med 7: 595-599

37. Pagano G, Bruno G (1991) Epidemiology and pathogenesis of diabetes in elderly. Arch Gerontol Geriatr [Suppl 2]: 209-218

38. Papoz L, Vauzelle F, Vexian P, Cathelineau G (1988) Pattern of treatment among diabetic patients in France. Diabetes Care 11: $586-591$

Received: 13 November 1991

and in revised form: 4 May 1992

Prof. G. Pagano

Institute of Internal Medicine

Corso Dogliotti 14

I-10126 Torino

Italy 